\title{
STRATEGI PROMOSI WISATA \\ PADA DINAS PARIWISATA KABUPATEN MAMASA
}

\author{
Idastin $^{1}$ Muhammad Abid ${ }^{2}$ \\ ${ }^{1}$ Prodi Ilmu Pemerintahan, Fakultas Ilmu Sosial dan Ilmu Pemerintahan \\ Universitas Al Asyariah Mandar \\ Email:bayusapuad@gmail.com \\ ${ }^{1}$ Prodi Ilmu Komunikasi, Fakultas Ilmu Sosial dan Ilmu Pemerintahan \\ Universitas Al Asyariah Mandar \\ Email: abid0401@gmail.com
}

\begin{abstract}
This study aims to determine the tourism promotion strategy at the Mamasa Regency Tourism Office. This research use desciptive qualitative approach. Data collection techniques obtained from observation, interviews and documentation. The results of his research show that the seven main strategies carried out by the Mamasa Regency Tourism Office have been implemented but all of them have not run optimally so the desired results have not been achieved according to the target. This is due to inhibiting factors, namely insufficient facilities and infrastructure; human resources are still lacking; lack of regulations and a strong legal basis to regulate Mamasa tourism; and forms of overlapping management between government, foundations or families and the private sector
\end{abstract}

\section{ABSTRAK}

Penelitian ini bertujuan untuk mengetahui strategi promosi wisata pada Dinas Pariwisata Kabupaten Mamasa. Penelitian ini menggunakan pendekatan deskriptif kualitatif. Teknik pengumpulan data diperoleh dari observasi, wawancara dan dokumentasi. Adapun hasil penelitiannya menunjukkan bahwa tujuh straregi pokok yang dilakukan oleh Dinas Pariwisata Kabupaten Mamasa telah terlaksana namun keseluruhannya belum berjalan secara maksimal sehingga hasil yang diinginkan belum tercapai sesuai target. Hal ini disebabkan oleh faktor penghambat yaitu sarana dan prasarana masih kurang memadai; sumber daya manusia masih kurang; kurangnya peraturan dan landasan hukum yang kuat untuk mengatur kepariwisataan Mamasa; dan bentuk pengelolaan saling tumpang tindih antara pemerintah, yayasan atau keluarga dan swasta.

Kata Kunci: Strategi, Promosi, Wisata. 


\section{PENDAHULUAN}

Sektor pariwisata merupakan alternatif pemasukan bagi pendapatan daerah maupun bagi devisa negara, bahkan bagi negara-negara maju sekalipun pariwisata serius untuk dikembangkan. Terkait dengan hal itu, dalam UndangUndang Republik Indonesia Nomor 9 Tahun 1990 menyatakan bahwa kepariwisataan mempunyai peranan penting untuk memperluas dan memeratakan kesempatan berusaha dan lapangan kerja, mendorong pembangunan daerah, memperbesar pendapatan nasional dalam rangka meningkatkan kesejahteraan dan kemakmuran rakyat serta memupuk rasa cinta tanah air, memperkaya kebudayaan nasional dan memantapkan pembinaannya dalam rangka memperkukuh jati diri bangsa dan mempererat persahabatan antar bangsa.

Kabupaten Mamasa yang terletak di Propinsi Sulawesi Barat juga memiliki keunikan pariwisata dan budaya tersendiri. Keunikan tersebut merupakan daya tarik pariwisata yang berupa wisata alam, seperti air terjun, hutan dan bukit. Wisata buatan, seperti waterpark dan monument. Wisata budaya, seperti rumah adat tongkonan dan prasasti. Sedangkan wisata minat khusus, seperti pendakian Tanete (gunung) Gandang Dewata, Tanete (gunung) Mambulilling (Dinas Pariwisata Kabupaten Mamasa, 17 Oktober 2012).

Dinas Pariwisata Kabupaten Mamasa merupakan unsur pelaksana Pemerintah Daerah di bidang kebudayaan dan kepariwisataan dan mempunyai tugas menyelenggarakan urusan rumah tangga Pemerintah Daerah di bidang kepariwisataan. Pelaksana tugas Dinas Pariwisata, adalah berusaha meningkatkan daya tarik wisata yang diharapkan akan meningkatkan jumlah kunjungan wisatawan, sehingga Dinas pariwisata dapat menyumbang Pendapatan Asli Daerah (PAD) sesuai target yang dibebankan oleh pemerintah Kabupaten Mamasa. Oleh karena itu, diperlukan suatu langkah nyata dalam menjalin saling pengertian dan kepercayaan dengan berbagai pihak dalam mengenalkan potensi wisata dan menarik wisatawan agar berkunjung (Dinas Pariwisata Kabupaten Mamasa, 17 Oktober 2012).

Berdasarkan data observasi awal yang diperoleh dari Dinas pariwisata Kabupaten Mamasa mengenai jumlah kunjungan wisatawan, terlihat adanya ketidakstabilan jumlah wisatawan dari tahun ke tahun. Ketidakstabilan tersebut terhitung mulai tahun 2007 dengan jumlah kunjungan di Mamasa adalah 105.544 orang. Kemudian turun menjadi 81.510 orang pada tahun 2008. Tahun 2009 mengalami banyak kenaikan menjadi 289.305 orang. Kemudian turun lagi menjadi 258.467 orang pada tahun 2010. Tahun 2011 mengalami kenaikan lagi menjadi 341.963 orang. 
Secara umum, jumlah kunjungan wisatawan di Kabupaten Mamasa terjadi penurunan pada tahun 2007-2008 sebesar 12,8\%, kemudian terjadi kenaikan jumlah kunjungan wisatawan yang cukup pesat pada tahun 20082009 sebesar 56\%, tahun 2009-2010 mengalami penurunan kembali sebesar $5,6 \%$ dan terjadi kenaikan kembali sebesar 13,9\%pada tahun 2010-2011. Hingga saat ini, jumlah kunjungan wisatawan ke Kabupaten Mamasa belum merata pada keseluruhan objek wisata yang ada. Hal tersebut dikarenakan belum dikenalnya objek-objek wisata lain di Mamasa.

Sejalan dengan persoalan objek wisata di Kabupaten Mamasa dalam usaha meningkatkan jumlah kunjungan wisatawan, maka keberadaan public relations pada Dinas pariwisata sangat diperlukan. Adanya bagian tersendiri yang khusus menangani masalah public relations akan lebih meningkatkan pelaksanaan komunikasi efektif yang akan mendukung pelaksanaan strategi promosi wisata Dinas pariwisata Kabupaten Mamasa.

\section{METODE PENELITIAN}

Penelitian ini merupakan penelitian deskriptif dengan pendekatan kualitatif yang bertujuan untuk menggali fakta tentang strategi promosi wisatapada Dinas pariwisata Kabupaten Mamasa.

Data atau informasi yang diperoleh dideskripsikan sesuai dengan kenyataan yang ada di lapangan dan disajikan dalam bentuk kata-kata atau kalimat kemudian ditarik suatu kesimpulan.

Adapun sumber datanya berupa data primer yang diperoleh dari observasi dan wawancara dari para informan, sedangkan data sekunder yaitu dokumentasi. diperoleh dari Kantor Pariwisata Kabupaten Mamasa serta jurnal dan buku pendukung lainnya terkait penelitian ini.

Penelitian ini dilaksanakan di Kantor Dinas Pariwisata Mamasa, Jalan Demmatande Mamasa. Waktu penelitian dimulai pada bulan Februari sampai Maret 2019.

\section{HASIL PENELITIAN}

Dalam mencapai sektor pariwisata yang unggul dan berkembang, tentulah dibutuhkan perencanaan yang mengatur dan mengelola agar sektor pariwisata ini dapat memberikan sebuah sumbangsih yang maksimal terhadapa daerah. Tidak hanya itu, diharapkan dari sektor pariwisata ini kemudian juga dapat meningkatkan kualitas hidup masyarakat. Sesuai dengan UU RI No. 10 Tahun 2009 Tentang Kepariwisataan dijelaskan pada:

a. Pasal 8: 1) Pembangunan kepariwisataan dilakukan berdasarkan rencana induk pembangunan kepariwisataan yang terdiri atas rencana induk 
pembangunan kepariwisataan nasional, rencana induk pembangunan kepariwisataan provinsi, dan rencana induk pembangunan kepariwisataan kabupaten/kota.

b. Pasal 11: Pemerintah bersama lembaga yang terkait dengan kepariwisataan menyelenggarakan penelitian dan pengembangan kepariwisataan untuk mendukung pembangunan kepariwisataan.

Atas dasar inilah, kemudian Pemerintah Kabupaten Mamasa dalam hal ini Dinas Periwisata membuat strategi pengembangan pariwisata kabupaten Mamasa yang tercantum dalam Rencana Induk Pengembangan Pariwsata Daerah (RIPPDA) Kabupaten Mamasa tahun 2011-2019.

Adapun capaian utama pengembangan pariwisata d Kabupaten Mamasa seperti yang disampaikan oleh Kepala Dinas Periwisata Kabupaten Mamasa Ibu Agustina Toding, S.Pd. M.Pd bahwa:

"Strategi pengembangan yang kita rumuskan dalam RIPPDA 20112019 ada 7 strategi, namun secara pokok capaian utama dari 7 strategi itu mengarah sesuai dengan visi dan misi kita secara umum, yakni diharapkan Mamasa dapat menjadi daerah tujuan wisata yang terkenal dengan kondisi alam dan budayanya yang khas, produk wisata yang ditawarkan kemudian diharapkan mendorong industri, usaha, dan jasa pariwisata semakin berkembang sehingga daya guna masyarakat setempat turut serta aktif dalam pengembangan pariwisata ini"

Tak jauh berbeda dengan yang disampaikan oleh Kepala bidang pengembangan pariwisata Dinas Periwisata Kabupaten Mamasa, Bapak Alfredi SE.M.Si di bahwa:

"Strategi yang ada di dalam RIPPDA itu merupakan landasan kita untuk mengembangkan pariwisata Mamasa terkhusus untuk bidang pengembangan pariwisata sendiri, tetapi yang perlu kemudian diingat bahwa capaian utama dari strategi ini nantinya adalah sektor pariwisata di Mamasa dapat diperhitungkan dan memberikan kontribusi yang besar terhadap daerah, memacu perkembangan pembangunan di Mamasa sendiri sehingga dari situ masyarakat Mamasa dapat hidup dengan sejahtera. Kemudian strategi ini direncanakan dilaksanakan selama 5 tahun dari tahun 2011-2019 dengan demikian perlu evaluasi kekurangan dan kelebihannya agar kedepannya harapan kita melalui evaluasi ini penyusunan RIPPDA selanjutnya bisa lebih baik"

Adapun strategi pengembangan pariwisata yang dirumuskan dalam RIPPDA Mamasa tahun 2011-2019 oleh Dinas Periwisata Kabupaten Mamasa adalah: 
1. Strategi dasar yang bersifat multipler effect atau strategi dengan berbagai effect

2. Strategi terkait dengan pengelolahan interest pariwisata

3. Strategi keterkaitan dan pengembangan produk

4. Strategi pemantapan pemasaran

5. Strategi pengembangan sumberdaya manusia

6. Strategi rasionalisasi pengembangan ruang wisata

7. Strategi pengembangan pariwisata bidang distribusi

\section{Strategi Dasar Bersifat Multipler Effect}

Strategi pengembangan ini dimaksudkan untuk memberikan dasar pengembangan pariwisata yang mempunyai dampak terhadap berkembangnya industri pariwisata yang terdiri dari:

a. Meningkatkan citra (image) dan identitas (identity) yang jelas tentang pariwisata Kabupaten Mamasa yang bernuansa wisata yang atraktif dan alami

b. Menciptakan dan mengembangkan produk wisata yang bernuansa kultural, natural, dan religius, yang mengarah ke wisata rohani dan budaya serta pengembangan wisata alam dan agro yang berwawasan lingkungan dengan keunikan tongkonan, erong, liang, dan tau-tau sebagai fenomena objek wisata yang unik.

c. Membuat suatu ketertarikan yang terpadu antara sosial budaya (unbiotic), lingkungan (biotic), dan ekonomi (economic), terhadap kemungkinan terciptanya suatu daya tarik wisata (DTW) yang berdaya guna dan berdaya saing tinggi.

d. Penciptaan dan pengembangan usaha-usaha pariwisata harus selektif dan akomodatif agar dapat mendukung usaha pengembangan sektor pariwisata

e. Memberikan rangsangan dan motivasi kepada pihak swasta atau perorangan untuk berusaha dalam bidang pariwisata

f. Mengembangkan wisata remaja dalam rangka penanggulangan kenakalan remaja

Pemaparan dari Kepala Dinas Periwisata Kabupaten Mamasa Ibu Agustina Toding S.Pd. M.Pd, menyatakan bahwa:

"Ya untuk strategi ini karna ini merupakan stratgei kunci menuju strategi lainnya saya rasa sudah berhasil $80 \%$ terlihat strategi ini kan memang dasar pengembangan, dimana dasar pariwisata di Mamasa yang perlu dikembangkan adalah dari segi wisata alam, seni dan budaya, sejarah, dan wisata agro yang berdampak pada objek-objek wisata mampu dikategorikan dan dibagi menurut jenisnya dan setelah itu tercipta lah produk-produk khas wisata Mamasa seperti bernuansa budaya yang natural dan berdaya saing kemudian dari situnyalah mampu menarik kunjungan dan usaha pariwisata, hanya saja satu poin dari 
strategi ini yang belum berjalan yakni pengembangan wisata remaja yang dimana karena mungkin pihak terkait yang mengelola dan mengurus belum maksimal."

Sama dengan yang disampaikan oleh Bapak Donatus, pengelola objek wisata Dona Dey bahwa:

"Sudah bagus memang jika pariwisata itu dikembangkan menggunakan hal-hal dasar supaya dengan begitu kalo ada dasarnya kan kita berlandasakan dari itu, kemudian jika dilihat hal-hal yang ingin dicapai dari strategi dasar ini sudah cukup bagus untuk mendukung perkembangan pariwisata di Mamasa, apalagi sudah semakin banyaknya objek wisata yang mulai dikenal kalo dari dasarnya sudah bagus otomatis ke depan strategi pengembangan yang lain pasti bagus. Saran saya cuma kalo bisa kita pengelola di ikut sertakan dalam pembuatan kalo ada rencana pengembangan seperti ini supaya kita bisa memberikan masukan"

Dari pemaparan ini, dapat dievaluasi bahwa strategi ini telah berjalan meskipun belum maksimal. Hal ini disebabkan masih ada satu poin capaian yang belum terlaksana dan juga penyusunan strategi belum melibatkan pengelolah secara umum, namun demikian strategi ini telah berjalan sesuai dengan yang telah direncanakan.

\section{Strategi Terkait dengan Pengelolahan Interest Pariwisata}

Strategi yang diharapkan untuk dapat mengembangkan aspekaspek yang berkaitan dengan pengembangan industri pariwisata meliputi:

a. Meluruskan usaha-usaha positif bernuansa wisata yang telah dilakukan sebelumnya, baik oleh pemerintah, swasta maupun perseorangan.

b. Dikembangkan sesuai dengan spesifikasi dan karakter wilayah dan lingkungan dalam strategi pemasaran melalui perencanaan yang terarah, terpadu dan terkendali.

c. Pengembangan jangkauan pasar wisata di dalam perencanaan seharusnya dirancang berdasarkan pengelolahan dan biro regional dalam kaitannya dengan interest wisata disetiap kecamatan agar terarah.

d. Peranan dan keterlibatan pihak swasta dalam penyelenggaraan pariwisata secara berkelanjutan sangat diharapkan.

e. Hubungan kerja dengan biro perjalanan harus lebih ditingkatkan terutama dalam skala lokal, nasional, maupun internasional.

Penjelasan dari Kepala Dinas Pariwisata Kabupaten Mamasa Ibu Agustina Toding S.Pd. M.Pd bahwa:

"Untuk strategi ini sebenarnya berjalan tapi yang maksimal itu hanyalah pada meluruskan usaha-usaha positif bernuansa wisata yang telah dilakukan 
sebelumnya juga kita kembangkan sesuai dengan spesifikasi dan karakter wilayah dan lingkungan Mamasa melalui perencanaan yang terarah, butkinya itu kita mampu menjalin kerjasama selama beberapa tahun dengan kepariwisataan provinsi dan pihak swasta dalam mengadakan event besar setiap tahun seperti Lovely December. Tapi kita seperti berdiam di tempat sebab acuan kita adalah mengikuti apa yang telah dilakukan sebelumnya, sehingga pada poin yaitu pasar pariwisata di tiap kecamatan itu tidak berjalan sama sekali hanya di kecamatan makale saja sebagai pusat kota yang pasar wisatanya berkembang"

Faktor yang mempengaruhi pengembangan pariwisata di Kabupaten Mamasa

Pengembangan sektor pariwisata merupakan suatu kegiatan yang dilakukan secara berencana, menyeluruh dan melibatkan berbagai aspek yang harus dilakukan secara terpadu dan terencana dengan baik. Dalam mengimplementasikan sebuah kebijakan, tidak akan terlepas dari faktor-faktor yang mempengaruhi dalam pelaksanaannya. Termasuk dalam pelaksanaan strategi yang telah direncanakan oleh Dinas Periwisata Kabupaten Mamasa untuk mengembangkan sektor pariwisata. Adapun faktor-faktor pendukung atau penghambat yang dihadapi dalam pelaksanaan strategi pengembangan pariwisata di Mamasa adalah sebagai berikut:

\section{Faktor Pendukung}

1. Alam dan Budaya Menunjang Kenaturalan Objek Wisata

Kabupaten Mamasa sendiri dikenal sebagai surga pegunungan, kondisi alam yang masih terjaga dan jauh dari hiruk pikuk perkotaan membuat Mamasa menjadi surga bagi para wisatawan yang ingin berwisata. Inilah yang menjadi salah satu modal utama yang mendukung sektor pariwisata di Mamasa yakni kondisi alamnya. Tak hanya itu budaya orang Mamasa yang beragam nahkan dikenal hingga ke mancanegara menjadi nilai jual tersendiri. Kepala Dinas Periwisata Kabupaten Mamasalbu Agustina Toding S.Pd. M.Pd mengatakan bahwa :

"Jikalau kita hendak membandingkan Mamasa dengan daerah wisata lainnya seperti di Bali ataupun Wakatobi Mamasa sebenarnya tertinggal jauh, tetapi jika dibandingkn objek wisatanya Mamasa mempunyai nilai jual tersendiri yakni kondisi alamnya yang terjaga dan masih alami, daerah pegunungan yang dingin dan masih jauh dari polusi, serta keadaan budaya yang beragam dan tak dapat dijumpai di daerah lain. Sebut saja budaya Rambu Tuka' atau upacara adat orang mati, hanya di Mamasa saja anda akan mendapati mayat yang di kubur di atas tebing batu setinggi puluhan meter, diupacarakan dengan adu kerbau yang memakan biaya ratusan juta. Budaya lain yang tak kalah nilai jualnya yaitu pesona perkampungan adat dimana rumah adat tongkonan yang 
unik berdiri tertata, serta kuburan alam berusia ratusan tahun yang masih terjaga"

Sama dengan yang disampaikan oleh pengelola objek wisata Permandian Air Panas yaitu Bapak Edi Sombolinggi bahwa:

"Sejak saya pertama kali ditugaskan oleh yayasan passanan tengko untuk bertugas mengelola objek wisata ini sejak 1998 kondisinya masih alami sampai sekarang, yayasan sudah melakukan pemugaran namun kenaturalannya tetap terjaga, sekalipun mungkin banyak objek wisata di daerah lain tetapi sampe sekarang objek wisata ini masih tetap diminati jika datang di Mamasa dan bahkan setiap tahun pengunjung semakin bertambah, atau "Na bolloanna mira sese" ( sebuah kalimat kiasan dalam bahasa Mamasa yang berarti tetap alami dan tak akan habis kecuali berkat dan rejekinya diputus oleh Tuhan)"

2. Kondisi Masyarakat dan Partisipasi Akan Sadar Wisata Tinggi

Kondisi masyarakat Mamasa yang dikenal memiliki budaya gotongroyong yang kuat membuat masyarakat Mamasa mampu hidup berdampingan dengan damai, tak hanya itu masyarakat Mamasa dikenal ramah terhadap sesamanya, sekalipun kental dengan gaya bahasa yang keras dan dominan menekan tetapi tidak kasar serta santun dalam berbahasa. Sekalipun kepercayaan diri orang Mamasa tergolong rendah dan cenderung pemalu namun dikenal ulet, mempunyai tingkat kesadaran tinggi dan kuat dalam bertanggung jawab. Seperti yang disampaikan oleh jepp salah seorang pengunjung objek wisata asal kota palopo bahwa:

"Orang Mamasa itu baik dan ramah saya sudah disini selama 2 malam berkesempatan berjalan-jalan kesini setelah datang mengikuti acara pernikahan teman, saya lihat masyarakat disini begitu bersatu menjalin hubungan, ketika acara pernikahan teman saya kemarin di rantepao semua saling membantu membuat pondok dan pelaminan, memasak, dan mempersiapkan acara pernikahan saya tanyakan ke saya punya teman kenapa yang datang banyak sekali bukan di kerja sama eo saja supaya gampang katanya memang sudah tugas bersama ketika ada acara para tetangga dan kerabat yang bekerja dan juga kesan waktu saya juga masuk ke objek wisata ini tadi pengelola dan para pedagang miniatur begitu ramah dan senyum kepada saya, jadi secara tidak langsung saya katakan tidak hanya objek wisatanya Mamasa yang bagus tetapi juga orangorang Mamasa baik hati dan menyenangkan dan yang tidak akan saya lupa kebersamaannya seperti ketika acara kemarin kami menikmati minuman ballo bersama sampai mabuk tetapi tidak saling mencederai"

Tak hanya kebersamaan dan adat istiadat yang terus dijaga oleh masyarakat Mamasa tetapi juga kesadaran terhadap sadar wisata. Kesadaran masyarakat Mamasa untuk mengembangkan sektor pariwisata dan menjaga 
kelestarian objek wisata, dari hasil yang dilihat peneliti di lapangan objek wisata yang dipilih menjadi fokus lokasi penelitian rata-rata objek wisata dikelola oleh keluarga dengan menjalin kerjasama dengan pemda, berikut tabel penjelasannya.

Tabel 1;

Pemilik dan Bentuk Pengelolaan Objek Wisata Yang Menjadi Lokasi Penelitian

\begin{tabular}{|c|l|l|}
\hline No & Nama Objek Wisata & \multicolumn{1}{|c|}{ Pemilik pengelola (bentuk pengelolaan) } \\
\hline 1 & Dona Dey & Keluarga Donatus \\
\hline 2 & Air Terjun Liawan & Pemerintah Kabupaten Mamasa \\
\hline 3 & Air Terjun Sambabo & Swasta \\
\hline 4 & Buntu Liarra & Pemerintah Kabupaten Mamasa \\
\hline 5 & Buntu Mussang & Swasta \\
\hline 6 & $\begin{array}{l}\text { Air Terjun } \\
\text { Lambanan }\end{array}$ & $\begin{array}{l}\text { Pemeriontah Daerah Mamasa. *di awal tahun } \\
\text { 2019 masyarakat sekitar objek telah } \\
\text { membentuk yayasan, telah dilakukan } \\
\text { pembicaraan dengan dinas terkait untuk } \\
\text { pengelolaannya }\end{array}$ \\
\hline 7 & To Pinus & Pemerintah Daerah Mamasa \\
\hline 8 & Perkampungan & Keluarga \\
\hline 9 & Bradisional & Keluarga \\
\hline
\end{tabular}

Sumber Data: Dinas Pariwisata Kabupaten Mamasa

Dari tabel ini dapat dilihat bahwa betapa tingginya partisipasi sadar wisata oleh masyrakat Mamasa. Salah seorang masyarakat di objek wisata Dona Dey yakni Bapak Daud Mangalik menjelaskan bahwa :

"Masyarakat asli disini melihat objek wisata ini sejak resmi dibuka di bulan oktober 2015 objek wisata Dona Dey menarik begitu banyak wisatawan tetapi tidak ada kemudian inisiatif dari pemda untuk proses pengelolaan baik itu penjualan karcis masuk dan penataan lokasi akhirnya kami sadar sebagai masyarakat asli di Suppiran kemudian berinisiatif sendiri mengelola objek wisata ini kami menata objek dengan membuka kios yang khusus masyrakat disini yang menjual, kami juga melakukan pendataan pengunjung yang datang dengan memasang portal sekalipun kami tidak mematok tarif masuk kami hanya meminta sumbangan sukarela kepada pengunjung yang datang untuk kami putar uangnya membeli karung, kantong sampah dan biaya makan siang kami setelah membersihkan dan apabila ada yang tersisa kami simpan sebagai kas yayasan."

\section{KESIMPULAN}


Strategi untuk pengembangan pariwisata yang direncanakan oleh Dinas Periwisata Kabupaten Mamasa berdasarkan 7 strategi pokok yaitu telah dilaksanakan namun ada yang berjalan secara maksimal ada juga yang belum berjalan secara maksimal sehingga hasil yang diinginkan belum tercapai karena dipengaruhi oleh banyak hal.

Adapun faktor yang mempengaruhi dalam pengembangan pariwisata di Mamasa adalah faktor pendukung berupa alam dan budaya menunjang kenaturalan objek wisata; kondisi masyarakat dan partisipasi akan sadar wisata tinggi; kondisi objek wisata memiliki nilai jual; promosi dan pasar pariwisata Mamasa sudah merambah hingga mancanegara. Sedangkan faktor penghambatnya ialah akses jalan dan sarana prasarana; sumber daya; kurangnya peraturan dan landasan hukum yang kuat untuk mengatur kepariwisataan Mamasa; dan bentuk pengelolaan saling tumpang tindih antara pemerintah, yayasan/keluarga dan swasta

\section{SARAN}

Dinas Pariwisata kabupaten Mamasa sebaiknya menganalisis lebih mendalam dalam penyusunan strategi selanjutnya terlaksana dengan baik; pengelola pariwisata sebaiknya dibina dan diperhatikan kualitas sumber daya manusianya; sarana dan prasarana perlu perhatian khusus dan pengembangan agar akses dan keperluan wisatawan yang berkunjung semakin berkualitas; kondisi alam dan budaya serta semangat sadar wisata masyarkat Mamasa harus dijaga dan dilestarikan agar pariwisata Mamasa tetap berkesan; daya tarik wisata dan nilai jual pada objek wisata harus dipertahankan; dan Pemerintah Daerah Kabupaten Mamasa sebaiknya memperbanyak kerjasama dengan investor, pihak sponsor, melakukan promosi ke berbagai pihak baik itu melalui media cetak maupun online untuk menarik kunjungan wisatawan serta membuat peraturan daerah yang khusus mengatur tentang pelaksanaan dan pengelolaan pariwisata di Mamasa agar Kepariwisataan Mamasa dapat tertata dan terlindungi karena memiliki landasan hukum.

\section{DAFTAR PUSTAKA}

Swastha, Basu \& Irawan. 1983. Manajemen Pemasaran Modern. Mamasa : Liberty.

Himna, Edwin Ismedi. 2013. Daya Tarik Wisatawan. Kedaulatan Rakyat (19 Januari 2013).

Garjito, Gunaning. 2005. Strategi Promosi Wisata Pada Dinas Pariwisata dan Kebudayaan Kabupaten Gunung Kidul. Skripsi. FIS-UNY.

Karyono, Hari. 1997. Kepariwisataan. Jakarta: PT. Remaja Rosdakarya. 
Rachmawati, Indria Desy. 2005. Strategi Publik Relations Dinas Pariwisata dan Kebudayaan Kabupaten Mamasa. Skripsi. FIS-UNY

Gitosudarmo, Indriyo. 2008. Manajemen Pariwisata. Mamasa : BPFE.

Kesrul. 2003. Penyelenggaraan Operasi Perjalanan Wisata. Jakarta : Garasindo.

Moleong, Lexi J. 2002. Metode penelitian Kualitatif. Bandung: Remaja Rosdakarya.

Miles M. B. dan Huberman, A. M. 1992. Analisis Data Kualitatif. Penerjemah: Tjetjep Rohendi Rohini. Jakarta : Universitas Indonesia.

Desky, M. A. 1991. Manajemen Perjalanan Wisata. Mamasa : Adicita Karya Nusa.

Yoeti. Oka A. 1996. Pengantar Ilmu Pariwisata. Bandung : Angkasa.

Effendy, Onong Uchjana. 1992. Hubungan Masyarakat Suatu Studi Komunikologis. Bandung: PT. Remaja Rosdakarya.

Kotler, Philip. 2001. Prinsip-prinsip Pemasaran. Jakarta: Erlangga

Nyoman S, Pendit. 2002. Ilmu Pariwisata Sebuah Pengantar Perdana. Jakarta: Pradnya Paramita.

Lupiyoadi, Rambat. 2006. Manajemen Pemasaran Jasa. Jakarta: Salemba empat.

Wahab, Salah. 2003. Manajemen Kepariwisataan. Jakarta: Pradnya Paranita. 